\title{
A IMPORTÂNCIA DA ELABORAÇÃO DO PLANO DE PARTO E SEUS BENEFÍCIOS
}

\author{
Kennya Nayane Torres ${ }^{1}$, Chennyfer Dobbins Abi Rached ${ }^{2}$ \\ 1 Especialista em Saúde da Família. Faculdade Unyleya - Brasilia - Brasil \\ 2 Doutora em Saúde Coletiva; Mestre em Economia da Saúde pela Universidade \\ Federal de São Paulo (UNIFESP); Docente do Programa de Mestrado Profissional em \\ Gestão em Sistemas de Saúde - Universidade Nove de Julho - UNINOVE. São Paulo - \\ Brasil email: chennyferr@yahoo.com.br ORCID: https://orcid.org/0000-0002-4499- \\ 3716
}

\section{RESUMO}

O parto natural consiste em um parto sem intervenções médicas desnecessárias, com o protagonismo da gestante e do bebê, sem analgésicos ou substâncias para acelerar as contrações. O nascimento no nosso país não é uma experiência natural, segundo a pesquisa Nascer no Brasil, pois $52 \%$ dos nascimentos são por cesariana. O plano de parto nada mais é do que um documento, feito pela a gestante, em maneira de carta ou preenchimento de um modelo pré-existente, contendo o que ela quer que aconteça ou não durante o seu parto, deixando registrado suas vontades. O principal objetivo deste trabalho foi desenvolver uma revisão bibliográfica sobre a temática "A importância da realização do Plano de Parto", condensando-se assim, informações e ideias que se têm publicado à cerca do mesmo. Este trabalho consistiu então, em uma Pesquisa Bibliográfica, com uma abordagem qualitativa. O levantamento bibliográfico foi feito a partir da análise em fonte tanto primária como secundária. Concluiu-se que o Plano de Parto, além de ser uma maneira de dar autonomia e empoderamento para a mulher gestante, auxilia a equipe de saúde que irá atende-la. Muitos são os profissionais que ainda desrespeitam o que é recomendado, e realizam procedimentos desnecessários, mesmo o plano de parto sendo sugerido pela a própria OMS. Salienta-se a importância e a necessidade de estudos e pesquisas sobre o plano de parto, pois infelizmente há escassez de publicações nacionais sobre o mesmo. Há escassez também relacionando o tema como ferramenta utilizada durante a assistência de enfermagem, evidenciando a necessidade de mais pesquisas nessa temática.

Descritores: Plano de Parto. Parto Natural. Enfermagem. Saúde da Família. Saúde da Mulher. 


\section{ABSTRACT}

The natural childbirth consists of a delivery without unnecessary medical interventions, with the protagonism of the pregnant woman and the baby, without analgesics or substances to accelerate the contractions. Birth in our country is not a natural experience, according to the survey Born in Brazil, because $52 \%$ of births are by cesarean section. The birth plan is nothing more than a document, made by the pregnant woman, in the form of a letter or filling a pre-existing model, containing what she wants to happen or not during her delivery, leaving her wishes registered. The main objective of this work was to develop a bibliographical review on the theme "The importance of the realization of the Childbirth Plan", thus condensing information and ideas that have been published about it. This work consisted, then, in a Bibliographic Survey, with a qualitative approach. The bibliographic survey was done from the analysis in source both primary and secondary. It was concluded that the Birthing Plan, besides being a way of giving autonomy and empowerment to the pregnant woman, assists the health team that will attend it. Many are professionals who still disrespect what is recommended, and perform unnecessary procedures, even the birth plan being suggested by the WHO itself. The importance and need for studies and research on the delivery plan is highlighted, as unfortunately there is a shortage of national publications about it. There is a shortage also relating the theme as a tool used during nursing care, evidencing the need for more research on this subject.

Keywords: Birth Plan. Natural childbirth. Nursing. Family Health. Women's Health.

\section{INTRODUÇÃO}

Um parto vaginal, sem intervenções médicas desnecessárias, com o protagonismo da gestante e do bebê, sem analgésicos ou substâncias para acelerar as contrações: este é o parto natural. O parto normal não significa o mesmo, pois ao usar o termo "normal", este está se referindo a apenas o parto ser por via vaginal. Já no parto natural, a mulher possui o maior controle possível sobre o seu corpo, participando ativamente no nascimento do bebê e tem o mínimo possível de intervenções durante 0 parto. O parto natural pode ser realizado no hospital, numa casa de parto ou em casa, acompanhado por profissionais de saúde.

Segundo Cortés (2015), as mulheres que passam pelo o parto natural, têm no final uma sensação de satisfação e superação profundas.

A maioria das técnicas de parto natural não é invasiva, portanto a possibilidade de efeitos colaterais nocivos para mãe e filho são mínimas. No parto natural não há perda de sensação, autonomia ou lucidez. A gestante tem 
a liberdade de se movimentar e achar posições que lhe ajudem a ficar mais confortável durante o parto. Ainda segundo Cortés (2015), comparando-se com as mulheres que tomam anestesia peridural, a gestante que se submete ao parto natural terá menos probabilidade de precisar de intervenções médicas, como o uso do hormônio ocitocina para intensificar as contrações, a colocação de uma sonda urinária, ou o uso de fórceps ou extração à vácuo. No parto natural também é possível que o parceiro possa participar do processo de controle da dor.

No parto natural é possível que a gestante elabore um plano para o caso de haver alguma eventualidade no parto, esclarecendo a equipe médica de em quais situações aceitaria receber medicação contra a dor, por exemplo.

O nascimento no nosso país não é uma experiência natural, segundo a pesquisa Nascer no Brasil, pois $52 \%$ dos nascimentos são por cesariana. Destes, $46 \%$ ocorrem no setor público e $88 \%$ na saúde suplementar (LEAL, 2014). Esses dados confrontam com o que é recomendado pela Organização Mundial da Saúde (OMS), de que apenas 10 a 15\% dos partos sejam realizados por meio desse procedimento (OMS, 2015).

Ainda que o acesso nas últimas décadas tenha apresentando melhorias, ainda há desafios, pois ainda persistem os indicadores de mortalidade materna, mortalidade neonatal e a prematuridade. Atrelado a isso, ainda há o excesso de medicalização, cesarianas e episiotomias. Estes, são responsáveis por parte evitável de complicações na atenção ao parto (VICTORA et al., 2011).

De acordo com o Ministério da Saúde (MS) e se utilizando de evidencias atuais, a humanização na atenção à gestante é garantia de um padrão de acesso e qualidade (BRASIL,2012). As práticas recomendadas na atenção ao parto atualmente ainda são as mesmas chamadas de "BOAS PRÁTICAS" pela OMS há vinte anos atrás. Estas possuem o objetivo de diminuir as intervenções desnecessárias, reforçando o conhecimento da fisiologia do corpo feminino para um nascimento natural e respeitoso (OMS,1996). Porém é possível observa ainda o desconhecimento ou até mesmo a omissão dessas práticas pelas equipes de saúde que atendem as gestantes no Brasil. Na maioria das vezes, a 
cena do parto é transformada em algo assustador, que transmite medo e é planejado não pela a mulher, mas sim pelos os profissionais.

O parto humanizado é um conceito que envolve basicamente o respeito que a mulher precisa no parto. Este parto reconhece a real necessidade da mãe e do bebê no parto. Segundo Guimarães (2018), todas as mulheres deveriam ter direito ao parto humanizado. De acordo com seus estudos, este respeito no parto envolve questões como:

\section{- Atender demandas na hora do parto:}

Isso inclui coisas simples, como oferecer água, lanches, permitir que a mulher vá ao banheiro quando quiser, entre outras demandas não causam qualquer problema no parto e inclusive são benéficas para o bem-estar da mãe.

- Permitir que a mulher fique na posição que mais achar confortável: Atualmente já está fortemente comprovado por pesquisas que parir deitada está longe de ser a melhor posição para o nascimento. Uma das posições mais indicadas costuma ser de cócoras. Mas acima de tudo, o importante é a mulher parir na posição que quiser. Isto é permitido no parto humanizado, pois a mulher pode parir na posição que se sentir melhor, podendo se movimentar durante o trabalho de parto. Esta ação contribui para o controle da dor.

\section{- Respeitar as escolhas sobre métodos para analgesia:}

Devem ser oferecidos para a mulher os métodos que ela desejar para aliviar a dor. Se só meios naturais, massagens, ou até mesmo anestesia, a escolha é dela.

\section{- Evitar procedimentos desnecessários na parturiente:}

Procedimentos como a episiotomia, corte do períneo, uso da ocitocina sintética para estimular o parto e cesárea só são orientados em situações muito específicas. Porém, sabe-se que a realidade do Brasil nos partos comuns, são feitos sem real necessidade. No parto humanizado, estes procedimentos só são feitos quando necessários.

- Evitar procedimentos desnecessários no bebê:

Durante e nas horas após o parto, seja ele o normal tradicional ou cesárea, o bebê pode sofrer uma série de procedimentos desnecessários que 
prejudicam sua saúde. No parto humanizado alguns destes procedimentos só são realizados quando há real necessidade.

\section{- Permitir a permanência da doula e obstetriz:}

A doula e a obstetriz são profissionais que além de dar assistência para a mãe, contribuem para uma boa e rápida evolução de trabalho de parto. Permitir a permanência delas durante o processo do nascimento é essencial para um parto com respeito.

\section{- Deixar mãe e filho juntos após o parto:}

Em partos tradicionais, principalmente cesáreas, é muito comum o bebê ser afastado da mãe após o nascimento. No parto humanizado se o bebê estiver bem, ele vai quase que diretamente e imediatamente para o colo da mãe após o nascimento.

\section{- Cordão umbilical:}

No parto humanizado o cordão umbilical geralmente não é cortado logo após o parto. Espera-se um tempo, no qual o bebê respira com o pulmão e o cordão, e só depois ele é cortado. Isso fará com que a transição da respiração seja menos traumática.

\section{- Aguardar a mulher entrar em trabalho de parto:}

Um dos principais pontos do parto humanizado é esperar a mulher entrar em trabalho de parto e não agendar ou realizar cesárea desnecessárias.

O parto humanizado é positivo tanto para mãe, quanto para o bebê. Este tipo de parto previne a violência obstétrica.

\section{- Evita que o bebê nasça prematuro:}

Segundo Guimarães (2016), "Quando o bebê está maduro, seu pulmão produz uma substância e isso faz com que a mãe entre em trabalho de parto. Se você consegue deixar a mulher entrar em trabalho de parto espontâneo, evita-se que o bebê nasça prematuramente".

\section{- Melhora a respiração do bebê:}

Durante a passagem do bebê pelo o canal vaginal, a compressão ajuda o bebê a colocar para fora todo o líquido dos pulmões. $O$ trabalho de parto é o processo final de amadurecimento pulmonar e assim, os riscos de 
complicações respiratórias são menores. Ao entrar em contato com a ocitocina o bebê nasce mais calmo e também alerta.

\section{- Menor risco de obesidade:}

Segundo uma pesquisa da Faculdade de Medicina de Ribeirão Preto da Universidade de São Paulo (USP), foi comprovado que o parto cesárea aumenta o risco de obesidade em adultos jovens. Isto se explica porque a cirurgia faz com que ocorram mudanças na microbiota intestinal dos bebês. Este fato porque estas crianças nascidas por meio de uma cesárea não passaram pelo canal vaginal, como acontece com os pequenos que vieram ao mundo via parto normal.

- Contato entre mãe e filho logo após o parto:

O parto humanizado estimula que logo após o parto, o bebê vá para o colo da mãe, desde que esteja bem, neste momento também é estimulada a primeira mamada. $\mathrm{O}$ contato pele a pele permite o bebê entrar em contato com as bactérias da pele da mãe. Além disso, o bebê irá sentir o calor da mãe e seus batimentos cardíacos, os mesmo que estava acostumado a ouvir dentro da barriga. Se foi parto vaginal as chances da mãe conseguir amamentar aumentam, segundo Guimarães (2016).

\section{- Menor risco de morte:}

De acordo com o Ministério da Saúde, que acompanhou parturientes entre 2000 e 2011, o risco de morte materna de quem realiza cesárea é cerca de 3,5 vezes maior do que das mulheres que optaram por parto normal.

\section{- Menor risco de infecção:}

Segundo o Ministério da Saúde, que acompanhou parturientes entre 2000 e 2011, o risco de infecção materna após o nascimento do bebê é cinco vezes menor em mulheres que optaram pelo parto normal do que aquelas que fizeram cesárea. Como não é um procedimento cirúrgico, o risco de infecção de mulheres que fizeram o parto normal é muito menor do que aquelas que optaram pela cesárea.

- O leite desce mais rápido:

A ocitocina liberada durante o parto normal irá contribuir para uma descida mais acelerada do leite materno.

- Relação mais próxima entre mãe e bebê: 
A ocitocina é conhecida como o hormônio do amor, isto porque ela estimula a relação mais próxima entre mãe e filho desde o início.

\section{- A recuperação é mais rápida:}

A mulher que realiza o parto vaginal terá uma recuperação muito mais rápida do que aquela que fez uma cesárea, já que este último é um procedimento cirúrgico.

\section{Parto normal $\mathrm{X}$ natural $\mathrm{X}$ humanizado}

É muito comum confundir o parto normal, o humanizado e o natural. $\mathrm{Na}$ realidade, o parto humanizado pode ser tanto normal quanto natural. $\mathrm{O}$ parto normal é o vaginal, mas que conta com alguns procedimentos, como o uso de anestesia. Já o parto natural, também é vaginal, mas não possui nenhum tipo de intervenção, então os métodos de alívio para a dor são todos naturais, a evolução do parto ocorre sem intervenções, entre outras questões. HÁpartos normais que podem contar com procedimentos desnecessários e que, portanto, não podem ser considerados humanizados.

Somos o país que mais realiza cesáreas no mundo, a maioria delas é feita sem necessidade. Além disso, a violência obstétrica contra a mãe e o bebê também é constante. Para evitar isto e garantir um parto humanizado, uma boa alternativa passa a ser montar um plano de parto.

\section{O Plano de Parto}

O plano de parto nada mais é do que um documento, feito pela a gestante, em maneira de carta ou preenchimento de um modelo pré-existente, contendo o que ela quer que aconteça ou não durante o seu parto, deixando registrado suas vontades. Ele surgiu nos Estados Unidos, há cerca de 30 anos atrás, como uma carta na qual a gestante escreve como prefere passar pelas diversas fases do trabalho de parto, como ela e o seu bebê devem ser tratados antes, durante e depois do nascimento. Nele estarão registrados quais procedimentos médicos a gestante aceita e quais prefere evitar.

Para Duarte (2016), a principal função do papel do plano de parto é a mulher saber que tem escolhas. Segundo ela, ao preenchê-lo, a gestante fará uma 
reflexão sobre o tipo de parto que prefere e, assim, estará mais preparada para conversar com o seu médico e saber se ele compartilha sobre os mesmos pensamentos. A gestante/parturiente tem o direito de participar das decisões que envolvem seu bem-estar e o do bebê, a menos que haja uma inequívoca emergência médica que impeça sua participação consciente. Ainda, a gestante possui o direito de saber exatamente os benefícios e prejuízos que cada procedimento, exame ou manobra médica pode provocar a ela e ao seu bebê.

Duarte (2016) trás que o ideal é que o plano de parto esteja pronto por volta do sétimo mês. Nisenbaum (2016) diz que o plano de parto é um instrumento interessante não só para a paciente, mas também para o médico, sendo importante conhecerem melhor as intenções de ambos os lados. Ele afirma ainda que o médico certamente se beneficiará de estar atendendo alguém mais preparado.

Sendo assim, o Plano de Parto consiste em uma carta ou uma lista simples, aonde a gestante lista tudo que gostaria ou não gostaria que acontecesse em seu trabalho de parto, pós-parto e primeiros cuidados com ela e com o bebê. $\mathrm{O}$ plano de parto se torna muito mais do que um documento, torna-se uma ferramenta para a gestante entrar em contato com os procedimentos relacionados ao parto e nascimento, e ainda, torna-se um diálogo prévio com a equipe de saúde que estará responsável pelo o seu cuidado.

Proposto pelo MS, um dos "10 Passos para o Pré-Natal de Qualidade" é o estimulo à elaboração do Plano de Parto pela gestante. Isto, a partir de informações fornecidas pelo profissional que faz o pré-natal, pré-natalista, sobre os benefícios do parto fisiológico. Mas, o conhecimento sobre o plano de parto e como implementa-lo ainda é escasso tanto no meio profissional quanto no meio acadêmico (BRASIL, 2012).

Desde 1996, o plano de parto é a $1^{\text {a }}$ Prática recomendada pela OMS como uma prática útil que deve ser encorajada: "deve ser um plano pessoal que determine onde e por quem o parto deverá ser atendido, feito pela mulher durante a gestação e conhecido pelo marido/parceiro e se possível, pela família" (OMS,1996, p.3). Ainda que recomendado pelo MS à todas as gestantes cadastradas no pré-natal e também incentivado pela OMS, a elaboração do 
plano do parto não é uma realidade no Brasil, gerando dificuldades e causando espanto em equipes de saúde que cuidam das gestantes nas unidades de Saúde e no Centro Obstétrico.

Além de assegurar a humanização da assistência, o plano de parto traz qualidade para o serviço que o utiliza, pois estará atendendo as escolhas definidas pela a gestante.

O plano de parto funciona da seguinte maneira: as mulheres escrevem, ou listam suas escolhas em relação ao seu parto e os primeiros cuidados com o recém-nascido. Formalizam em documento entregue e discutido com a equipe de saúde no momento do parto. É importante que durante toda a gestação, as mulheres recebam todas as informações sobre os seus direitos e também sobre as práticas recomendadas para a segurança no nascimento de seus filhos.

$\mathrm{Na}$ Espanha por exemplo, o plano de parto teve resultados positivos nas taxas de parto normal, contato pele a pele e clampeamento tardio do cordão. $O$ resultado foi que os gastos com internações da mãe e do bebê em Unidade de Terapia Intensiva neonatal foram reduzidos. Este mesmo estudo ainda demonstrou que o empoderamento das parturientes teve uma nova dimensão, por conta da autonomia que o plano de parto trás as mulheres e consequentemente o aumento da satisfação com o serviço. (CORTÉS et al.,2015)

Segundo CECATO (2016), em uma pesquisa realizada pela a mesma sobre a construção de plano de parto em Unidade Básica de Saúde, "O plano de parto traz a mulher o protagonismo da luta pelo direito de conhecer e decidir sobre o seu corpo e seu bebê. A construção do plano de parto permitiu um vínculo da gestante e sua família com a equipe da atenção básica e certeza de suas escolhas, o que se pode traduzir em empoderamento feminino."

A atuação do enfermeiro na consulta de pré-natal é de suma importância para a garantia de uma assistência integral e de qualidade. É por meio desta que se pode garantir a extensão da cobertura, além de subsidiar a construção de relações de comunicação, que serão úteis para o acompanhamento e 0 acolhimento dessa gestante, em todas as fases do seu processo de gestar e parir. Durante a consulta de enfermagem, o enfermeiro pode fornecer 
orientações e informações, visando o empoderamento dessa mulher e contribuindo para que se torne mais ativa durante todo o processo.

Sendo assim, diante das ideias apresentadas e sabendo que, a gestante possui o direito de saber de todas as informações beneficentes a ela, sendo o Plano de Parto um deles, dando-Ihe direito de escolha e autonomia, este trabalho visa a responder algumas questões norteadoras, juntamente com uma revisão bibliográfica a cerca desta temática.

\section{Objetivo Geral}

O principal objetivo deste trabalho é desenvolver uma revisão bibliográfica sobre a temática "A importância da realização do Plano de Parto", um instrumento que pode ocorrer no pré-natal realizado nas Unidades Básicas de Saúde, condensando-se assim, informações e ideias que se têm publicado à cerca do mesmo.

\section{Objetivos específicos}

- Definir e caracterizar o que é o Plano de Parto, definindo as dificuldades da realização do mesmo;

- Caracterizar as dificuldades dos profissionais de saúde que realizam o prénatal, na hora de pôr em prática o Plano de Parto;

- Definir como pode ser feito o incentivo à elaboração do Plano de Parto durante o pré-natal, demonstrando sua importância para a gestante;

- Relatar os benefícios que o Plano de Parto pode trazer para as mulheres;

- A importância da enfermagem para a execução do Plano de Parto. 


\section{Método}

Este trabalho consiste em uma Pesquisa Bibliográfica, com uma abordagem qualitativa. O levantamento bibliográfico foi feito a partir da análise em fonte tanto primária como secundária. A abordagem qualitativa, consiste em um método de investigação qualitativa científica que foca no caráter subjetivo do objeto analisado, estudando suas particularidades.

As fontes consultadas consistiram em artigos científicos encontrados na base de dados da Scielo, utilizando palavras chaves como "plano de parto", "parto humanizado" e "parto natural". Também foi realizado busca de monografias, trabalhos de conclusão de curso e reportagens de revistas utilizando as mesmas palavras chaves no Google.

\section{REVISÃO DA LITERATURA: OPÇÕES DO PLANO DE PARTO}

São várias as opções e escolhas da gestante para incorporar no seu Plano de Parto. Assim como também são muitos os benefícios promovidos por ele. A seguir, é apresentado algumas destas opções, citados por diversos autores em suas pesquisas.

\section{Acompanhante}

A Lei do Acompanhante (Lei Federal $n^{\circ} 11.108$, de 07 de abril de 2005) ficou conhecida como a Lei do Acompanhante. Esta, determina que os serviços de saúde do SUS, da rede própria ou conveniada, são obrigados a permitir à gestante o direito a acompanhante durante todo o período de trabalho de parto, parto e pós-parto.

Durante a elaboração do Plano de Parto, a gestante já pode optar se irá querer um acompanhante e escolher quem. O profissional pré-natalista poderá já a partir desse momento explicar os benefícios de se ter um acompanhante durante todo o trabalho de parto. Segundo CECATO (2016), "o acompanhante traz os benefícios de um tempo de trabalho de parto mais curto, reduz a analgesia e a possibilidade de cirurgia cesariana." Ainda, proporciona uma maior satisfação materna com o serviço, e para o recém-nascido escalas de Apgar maiores que 7 no quinto minuto de vida (HODNETT et al., 2013). 


\section{Movimentação}

Na elaboração do plano de parto, a vontade de livre movimentação já poderá ser manifesta, uma vez que é dever dos profissionais de saúde explicar a gestantes todas as posições benéficas durante o trabalho de parto. Segundo uma pesquisa realizada por CECATO (2016), a não livre movimentação durante a estadia no Centro Obstétrico, foi vista como um dos piores impedimentos pela as gestantes.

A liberdade de poder movimentar-se como quiser, influencia durante 0 trabalho de parto, de maneira positiva. LAWRENCE et al (2013) comprovaram que a livre deambulação e posição vertical diminuem o tempo do primeiro estágio de trabalho de parto, diminui o uso da anestesia epidural e a cirurgia cesariana. Há evidências que essa prática também reduz o número de internações dos recém-nascidos em unidades neonatais.

\section{Episiotomia}

Episiotomia consiste em uma incisão efetuada na região do períneo (área muscular entre a vagina e o ânus) para ampliar o canal de parto. Desde 1996, a Organização Mundial da Saúde (OMS) no desenvolvimento de orientações sobre as melhores ações na condução do parto normal, baseada em evidências científicas, encaixou o uso liberal e rotineiro de episiotomia na categoria de "práticas frequentemente utilizadas de modo inadequado".

No Brasil, infelizmente, a taxa de episiotomia é alta. Isso foi demonstrado nos dados divulgados pela pesquisa Nascer no Brasil, realizada com mais de 23 mil mulheres pela Fundação Oswaldo Cruz em parceria com o Ministério da Saúde, monstrando que, entre as entrevistadas que tiveram parto normal, mais da metade $(53,5 \%)$ passaram por episiotomia. Em mulheres de baixo risco obstétrico, essa taxa foi ainda mais lamentável, 56\%. Pra se ter ideia de como esse dado é assustador, a OMS relata que apenas $10 \%$ dos partos normais teria real indicação.

Uma ONG mundial que revisa publicações da medicina, localizada na Biblioteca de Cochrane, possui pesquisas que mostram que a episiotomia pode trazer complicações graves, dentre elas a laceração e frouxidão na região 
perineal, que, consequentemente, levam a problemas intestinais ou, até mesmo, na contenção de órgãos incluindo o intestino (BASILIO, 2014).

Segundo a obstetra do Instituto de Medicina Professor Fernando Figueira (PE), Melania Amorim (2014), "Não há respaldo científico para as supostas indicações da episiotomia. Há evidências de que a incisão aumenta o risco de lesão perineal sem benefícios." Ainda segundo pesquisas da mesma, existem estratégias para deixar a musculatura mais elástica e facilitar o parto normal, dentre elas: massagem, pompoarismo e exercícios físicos mais leves, como caminhada.

CECATO (2016) trás em sua pesquisa que a restrição da episiotomia nos serviços de saúde diminui os riscos de trauma perineal grave, trauma posterior, trauma anterior, sutura perineal, dor e infecção perineal.

Todas essas informações devem ser passadas pelo o profissional de saúde pré-natalista a gestante, e durante a elaboração do Plano de Parto, a mesma já poderá indicar a não-realização do procedimento caso este seja sem indicação durante o seu parto.

\section{Enema}

Consiste na introdução de água e/ou medicamentos líquidos no organismo por via retal, ou seja, é uma lavagem intestinal. Segundo achados científicos, o uso de enema é contra-indicado, uma vez que não tem efeito sobre infecções neonatal e puerperal, não previne a eliminação de fezes no primeiro e segundo estágio de trabalho de parto e não afeta a duração do trabalho de parto nem a dinâmica uterina (REVEIZ; GAITÁN; CUERVO, 2013).

Sendo assim, no plano de parto a mulher pode manifestar o desejo contra a realização deste procedimento.

\section{Tricotomia}

A tricotomia consiste na retira dos pelos da região íntima. A mulher poderá manifestar o desejo a favor ou contra este procedimento no seu plano de parto.

Em relação a esta temática, foram realizados três ensaios clínicos randomizados com 939 mulheres onde se concluiu que não houve diferença na 
morbidade febril materna e nem nas taxas de infecção e deiscência perineal. Isto demonstra que as evidências cientificas para que se recomende tricotomia de rotina são insuficientes. (BASEVI; LAVENDER, 2009).

\section{Dieta}

No Brasil e em vários países, por muito tempo, não era oferecido nenhum tipo de alimentação durante o trabalho de parto. Atualmente, não existe evidência cientifica para o jejum durante o trabalho de parto de baixo risco.

Singata, Tranmer e Gyte (2013) utilizaram cinco ensaios clínicos randomizados com 3.130 mulheres por meio dos quais evidenciou-se que a restrição de alimentos e líquidos não influencia nas taxas de cesáreas, partos instrumentais, Apgar menor que sete e duração do parto. O motivo mais citado como justificativa por profissionais que atendem as mulheres em Centros Obstétricos são náuseas ou a ocorrência da Síndrome de Mendelson se fosse necessária uma anestesia geral, porém de todas as mulheres incluídas nesses estudos nenhuma foi afetada. Este estudo é citado em vários artigos científicos e é a fonte para muitos profissionais se respaldarem.

A gestante pode optar no seu plano de parto para receber alimentação e líquido.

\section{Ocitocina}

A mulher pode escolher se quer a infusão ou não de Ocitocina. CLARK et al. (2009) descreve em seu estudo que para ter a infusão da Ocitocina devem ser seguidos alguns passos, como a discussão com a mulher sobre a indução eletiva do trabalho de parto, incluindo seus riscos e benefícios. Ainda segundo ele, a regulação da dosagem da ocitocina deve ser focada na resposta uterina e fetal e quando instalada deve permanecer com a mulher um profissional que avalie a infusão e ação da droga. 


\section{BENEFícIOS PROMOVIDOS PELA A ELABORAÇÃO DO PLANO DE PARTO:}

\section{Escuta Qualificada e Acolhimento}

A escuta qualificada é um dos principais meios utilizados nas consultas prénatal, pois é uma forma de acolher a gestante e sua família. Essa ferramenta proporciona confiança da mulher na equipe de saúde, já que representa o respeito à diversidade e singularidade (RAIMUNDO; CADETE, 2012).

Essa escuta não é só apenas ouvir a gestante, é uma escuta aberta, onde a gestante pode conversar à vontade sobre sua intimidade com segurança, o que fortalece o vínculo com a equipe de saúde e proporciona conhecimento sobre si mesma (BRASIL, 2012).

Já o acolhimento é uma tecnologia leve, utilizada para facilitar o acesso da usuária, o que faz aumentar a adesão ao pré-natal. A resolutividade é um dos objetivos do acolhimento pré-natal, ouvindo a usuária e garantido o acesso a outros serviços, respeitando o cuidado integral. Cabe a equipe de saúde, no serviço ou na comunidade, buscar compreender o contexto psicossocial da gestante (BRASIL, 2012).

\section{Boas práticas}

Ao estar elaborando o plano de parto, estará em comprimento as "Boas Práticas" recomendadas pela a OMS. Estará em prática ainda, ações para beneficiar a gestante, nesse momento que deve ser marcado como algo prazeroso e natural, e não com marcas e lembranças de procedimentos desnecessários, sem conhecimento ou autorização da mulher.

A literatura aponta o PP como um componente educativo de alto potencial, uma vez que tem a capacidade de melhorar a comunicação entre os profissionais envolvidos nessa assistência e a usuária.10-12 No que tange ao seu caráter educativo, o PP possibilita à mulher o acesso a informações, subsidiando a construção de conhecimentos indispensáveis para a tomada de decisão sobre o parto e o nascimento do seu filho. 


\section{CUIDADOS COM O RECÉM-NASCIDO}

As três práticas recomendadas no manual intitulado: Além da Sobrevivência da Organização Pan-americana de Saúde (OPAS) que o MS divulgou no Brasil são: o clampeamento tardio do cordão umbilical, o que proporciona ao recémnascido um maior aporte sanguíneo e de ferro, diminuindo as hemorragias intraventriculares e sepse; contato pele a pele entre mãe e bebê, pois assegurar esse contato garante regulação térmica, vínculo e maior efetividade da primeira mamada; e início precoce da amamentação, logo após o parto, pois já esse método possibilita prevenção da mortalidade neonatal e aumenta as chances de um período de amamentação duradoura e exclusiva. (BRASIL,2011).

\section{ELABORAÇÃO DO PLANO DE PARTO E EMPODERAMENTO DA MULHER}

Dentre as principais ferramentas para o empoderamento da mulher no processo de gestar e parir, destaca-se o plano de parto, que pode ser elaborado e planejado a partir das demandas da mulher com o auxílio dos profissionais da área de saúde, principalmente o enfermeiro. Isso é o que trás Nogueira et.al. (2017).

Desde novas e muito pequenas, as mulheres estão acostumadas a relacionar o parto a algo ruim e doloroso. A Humanização do parto vem para quebrar isso, e é um processo que pode ser chamado de um espetáculo, como bem coloca Jordano (2017), onde a mulher é a protagonista e a sua vontade e o seu bem estar, juntamente com o bem estar de seu bebê, são de extrema importância durante todo o processo.

Jordano (2017) diz que no passado, as mulheres tinham muita vergonha de falar sobre as mudanças que ocorrem na genitália enquanto estão grávidas. Muda o tamanho, o muco, a lubrificação, a relação com o sexo. Atualmente, as mulheres se sentem mais empoderadas para falar com muita simplicidade e normalidade. Falam também sobre as várias fases por que passam, como o medo, a dor, o amor. Antes, as mulheres eram muito focados no mito do amor materno. Como se, ao ficar grávida, a mulher precisasse amar tudo e não é 
assim. É como qualquer outra fase na vida. A autora trás que é preciso ter respeito aos limites emocionais, relacionais da mulher.

Segundo Jordano (2017), parto é um momento único na vida de uma mulher e o conceito de parto humanizado busca trazer de volta essa individualidade do parto, atendendo a mulher dentro de suas necessidades e vontades naquele momento. A autora diz que se esse fosse um processo fisiológico, todos os partos seriam iguais, mas o que faz com que um momento seja diferente do outro é exatamente essa individualidade, a história de cada mulher. A autora destaca ainda que esse novo tipo de assistência se baseia no atendimento por equipes transdisciplinares e horizontais, sendo profissionais como médico obstetra, enfermeira, pediatra, doula, etc., trabalhando juntos, cada um dentro de seu papel, sem hierarquias.

Dentro do parto humanizado, existem 3 pilares essenciais: respeito ao tempo do bebê e da mulher, aguardando o tempo natural para o parto acontecer; protagonismo da mulher, respeitando suas escolhas quando há possibilidade de escolhas, fazendo com que ela tenha liberdade para vivenciar o momento da melhor forma possível; e também há o compartilhamento de responsabilidades com base em evidências científicas, quebrando paradigmas e aplicando novas descobertas para que seja feito o que é melhor segundo a ciência. Este pensamento é baseado nos estudos de Jordano (2017).

O incentivo e elaboração do plano de parto deve se dá em todo o pré-natal, não somente em consultório, mas também pode ser feito na comunidade em visitas domiciliares e coletivamente em grupos de gestantes. É aí que pode entrar a Estratégia Saúde da Família, incentivando a elaboração do plano de parto durante as consultas nas casas, fortalecendo desde aí o vínculo entre a equipe e a gestante.

O plano de parto deve ser elaborado pela mulher a partir principalmente de informações fornecidas pela equipe, sempre se baseando nas boas práticas recomendadas pela OMS (1996). As informações também devem ser prestadas para seu acompanhante e familiares.

Todas as gestantes devem ser ouvidas e informadas sobre qualquer procedimento que se fizer necessário. Sempre deve-se deixar claro que o parto 
pode tomar outro rumo que não o desejado pela mulher, porém o motivo para a intervenção deve ser conhecido por ela e seu acompanhante.

Segundo Santos, 2016, "Do século XX para cá, definiu-se que a forma de lidar com o corpo da mulher é com força. Corpo de mulher não precisa de força. É só o contato, pele a pele". Os profissionais devem passar as informações sobre o funcionamento natural do corpo feminino durante o parto. Cabe à mulher observar limitações próprias anatômicas, fisiológicas e do bebê para fazer suas escolhas. A categoria que está mais apta para se qualificar para o parto com minimização de risco, para o parto humanizado, é a da enfermagem. Isso porque não tem medicalização, procedimento cirúrgico.

O empoderamento da mulher sobre o seu corpo e gestação são essenciais para produção do plano de parto, pois assim elas se sentem livres para fazerem suas escolhas.

\section{MODELOS DE PLANOS DE PARTO}

A seguir é apresentado alguns modelos de planos de parto: 


\section{Plano de Parto}

Você quer a presença de pessoas durante o parto?

( ) $\operatorname{sim}$ ( ) não

Quem você quer presente durante o parto?

Você quer tricotomia (raspagem dos pelos pubianos)?

( ) $\operatorname{sim}($ ) não

Você quer enema (lavagem intestinal)?

( ) $\operatorname{sim}($ ) não

Você quer perfusão contínua de soro?

( ) $\operatorname{sim}($ ) não

Você quer água e sucos enquanto forem tolerados?

( ) $\operatorname{sim}($ ) não

Você quer perfusão contínua de ocitocina?

( ) $\operatorname{sim}($ ) não

Você quer escolher a posição em que quer ficar?

( ) $\operatorname{sim}($ ) não

Você quer fazer caminhadas?

( ) $\operatorname{sim}($ ) não 
Você quer uso ilimitado de banheira ou chuveiro?

( ) $\operatorname{sim}($ ) não

Você quer monitoramento fetal contínuo?

( ) $\operatorname{sim}$ ( ) não

Você quer que a bolsa seja rompida artificialmente?

( ) $\operatorname{sim}($ ) não

Você quer analgesia?

( ) $\operatorname{sim}$ ( ) não ( ) apenas se solicitado

\section{Parto}

Qual posição você prefere?

( ) deitada ( ) cócoras ( ) semissentada

Você gostaria de ser guiada, na hora de fazer força?

( ) $\operatorname{sim}($ ) não

Você quer epistomia (corte no períneo)?

( ) $\operatorname{sim}($ ) não

As luzes da sala de parto devem ser apagadas na hora do nascimento?

( ) $\operatorname{sim}($ ) não

O bebê deve ser colocado no peito logo após o nascimento para mamar?

( ) $\operatorname{sim}($ ) não 
Quem cortará o cordão umbilical?

( ) pai ( ) médico

O bebê deve ficar no quarto com você o tempo todo, a não ser que você solicite a retirada dele?

( ) $\operatorname{sim}($ ) não

Cuidados com o bebê

O nitrato de prata e antibióticos oftálmicos devem ser aplicados?

( ) sim ( ) não ( ) apenas se necessário

Você quer administração de vitamina K oral?

( ) $\operatorname{sim}($ ) não

Você quer amamentação sob livre demanda?

( ) $\operatorname{sim}($ ) não

Você autoriza o uso de água glicosada, bicos ou outros ao bebê?

( ) $\operatorname{sim}($ ) não

Você autoriza que as enfermeiras troquem ou deem banho no bebê?

( ) $\operatorname{sim}($ ) não

Quem pode trocar e dar banho no bebê?

Em caso de cesárea

Você quer ser sedada durante o parto?

( ) $\operatorname{sim}($ ) não 
Você prefere esperar pelo trabalho de parto antes de se resolver pela cesárea?

( ) $\operatorname{sim}($ ) não

Você quer a presença de pessoas durante o parto?

( ) $\operatorname{sim}($ ) não

Quem você quer presente?

Qual tipo de anestesia você prefere?

( ) peridural ( ) raquidiana

Você quer que o campo seja abaixado durante o parto?

( ) $\operatorname{sim}($ ) não

As luzes da sala de parto devem ser reduzidas?

( ) $\operatorname{sim}($ ) não

Você quer que suas mãos fiquem livres durante o parto?

( ) $\operatorname{sim}($ ) não

O bebê deve ser colocado no peito logo após o nascimento?

( ) $\operatorname{sim}($ ) não

Você quer que o bebê fique com você durante a sutura?

( ) $\operatorname{sim}($ ) não

Figura 1: Plano de Parto inspirado no modelo do livro "Parto Normal ou Cesárea - Tudo O Que As Mulheres Deveriam Saber", de Ana Cristina Duarte e Simone Diniz (Unesp) 2016. 


\begin{tabular}{|l|l|}
\hline \multicolumn{2}{|c|}{ Plano de Parto } \\
\hline $\begin{array}{l}\text { Cara equipa obstétrica, reunimos neste documento as nossas preferências de parto } \\
\text { (para condições consideradas normais) na esperança de criar a melhor experiência } \\
\text { possível para todos os intervenientes. Gratos antecipadamente pela vossa atenção } \\
\text { e profissionalismo. }\end{array}$ \\
\hline Local do parto & \\
\hline Nome e contato do acompanhante & \\
\hline Nome e contato do cuidador de saúde & \\
\hline Nome e contato da doula & \\
\hline Uso de água & \\
\hline Alívio da dor & \\
\hline Posições & \\
\hline $3^{\text {a fase do parto }}$ & \\
\hline Procedimentos ao bebê & \\
\hline Luzes, música, temperatura & \\
\hline Bebida / comida & \\
\hline Observações & \\
\hline
\end{tabular}

Figura 2: Plano de parto tipo tabela. Este plano de parto foi elaborado tendo como pressuposto o princípio geral de Direito no qual o "consentimento pessoal é necessário para todas as intervenções médicas" plasmado no artigo $5^{\circ}$ da Convenção dos Direitos do Homem e Biomedicina (Convenção de Ovíedo) assinada e ratificada por Portugal (em vigor desde 1 de dezembro de 2001). Salvaguarda-se a incapacidade da tomada de decisão numa emergência médica, em que o profissional de saúde pode agir de forma a salvaguardar a vida do paciente. 


\section{Plano de Parto}

NOME:

ENDEREÇO:

TELEFONE:

E-MAIL:

DATA:

\section{Durante o Trabalho de parto:}

1. Presença de um acompanhante de minha preferência, conforme a Lei $11.108 / 2005$

( ) SIM ( ) NÃO

2. Uso contínuo de Soro e Ocitocina Sintética

( ) SIM ( ) NÃO

3. Liberdade para beber água e sucos enquanto seja tolerado.

( ) SIM ( ) NÃO

4. Liberdade para caminhar e mudar de posição.

( ) SIM ( ) NÃO

5. Monitoramento fetal: apenas se for essencial, e não contínuo.

( ) SIM ( ) NÃO

6. Raspagem dos pelos pubianos

( ) SIM ( ) NÃO

7. Analgesia somente quando eu pedir.

( ) SIM ( ) NÃO

\section{Parto (hora do nascimento):}

8. Liberdade para escolher a posição que me sentir melhor:

( ) SIM ( ) NÃO 
9. Episiotomia (corte na vagina) - somente se necessário com justificativa:

( ) SIM ( ) NÃO

10. Manobra de Kristeller (profissional de saúde faz pressão no fundo do útero para empurrar o bebê para fora):

( ) SIM ( ) NÃO

11. Ruptura artificial de bolsa, por rotina:

) SIM ( ) NÃO

12. Amarração dos braços e das pernas durante o parto:

( ) SIM ( ) NÃO

13. Bebê imediatamente colocado no colo para o contato pele a pele:

( ) SIM ( ) NÃO

\section{Após o parto:}

14. Aguardar expulsão espontânea da placenta com auxílio da amamentação

( ) SIM ( ) NÃO

15. 0 bebe deve ficar comigo o tempo todo, mesmo para avaliação e exames.

( ) SIM ( ) NÃO

16. Alta o quanto antes.

( ) SIM ( ) NÃO

Caso a cirurgia cesariana seja necessária.

17. Presença do acompanhante:

( ) SIM ( ) NÃO

18. Anestesia: peridural, sem sedação.

( ) SIM ( ) NÃO

19. Ver a hora do nascimento, com o rebaixamento do protetor ou por um espelho.

( ) SIM ( ) NÃO 
20. Após o nascimento, colocar o bebê sobre o peito e que as mãos estejam livres para segurá-lo

( ) SIM ( ) NÃO

21. Amamentação o quanto antes.

( ) SIM ( ) NÃO

Cuidados com o bebê:

22. Amamentação na primeira hora de vida:

( ) SIM ( ) NÃO

23. Oferecimento de água glicosada ou leite artificial:

( ) SIM ( ) NÃO

24. Alojamento conjunto o tempo todo.

( ) SIM ( ) NÃO

25. Colírio de nitrato de prata quando os exames de Streptococo, Clamídia e Gonorreia forem negativos:

( ) $\operatorname{SIM}$ ( ) NÃO

Esse é meu Plano de Parto, que protocolo neste momento para que minha vontade e autonomia sejam atendidas. Solicito que procedimentos em desacordo com o aqui expressamente descrito sejam devidamente justificados no meu prontuário médico.

Assinatura dos pais:

Protocolo do hospital:

Recebido em:

Por (nome e função):

Hospital:

Figura 3: Plano de parto elaborado pela Artemis em parceria com a Defensoria Pùblica do Estado de São Paulo. 


\section{CONSIDERAÇÕES FINAIS}

Diante das ideias apresentadas, considera-se que o Plano de Parto, além de ser uma maneira de dar autonomia e empoderamento para a mulher gestante, auxilia e equipe de saúde que irá atende-la, para saber como agir e como não agir em caso de parto de baixo risco, aonde pode ser respeitado todas as escolhas da mulher.

Vemos também que mesmo diante de todas as evidências apresentadas, muitos são os profissionais que ainda desrespeitam o que é recomendado, e realizam procedimentos desnecessários. Mesmo o plano de parto sendo sugerido pela a própria OMS, ainda é desconhecido pela a gestante, pela a equipe de saúde e pelas as instituições.

A elaboração do plano de parto no pré-natal é uma ferramenta de apoio às boas práticas, que infelizmente ainda é muito pouco utilizada. O plano de parto traz a mulher o protagonismo da luta pelo direito de conhecer e decidir sobre o seu corpo e seu bebê.

O Plano de parto tem como objetivo orientar e preparar não apenas a mulher e seu respectivo cônjuge, mas também a equipe de saúde que atenderá o parto. Além disso, precisa evidenciar os procedimentos que geram conforto à parturiente e aqueles indesejáveis, sendo que a mulher também deve ser comunicada, caso ocorra qualquer alteração que necessite de intervenção.

Santos (2016), trás que o maior desafio para o parto humanizado na atualidade e a elaboração de um plano de parto são os profissionais que não abordam a mulher como sujeito político, no sentido de que cabe a ela autoridade sobre seu corpo. A mulher tem o poder e o direito de decidir sobre ele. Existem políticas, regras, regulamentos federais, distritais e internacionais sobre o tema. A questão é respeitá-los.

A formação é outro desafio. Existem estudos que comprovam os benefícios do parto humanizado. Esse inclusive é o foco da ${ }_{2}$ Rede Cegonha, uma iniciativa do Ministério da Saúde para saúde materno-infantil]. É necessário humanizar para quebrar a violência no parto. Muitos profissionais não querem reconfigurar suas práticas sobre o parto. 
A categoria que está mais apta para se qualificar para o parto com minimização de risco, para o parto humanizado, é a da enfermagem. Isso porque não tem medicalização, procedimento cirúrgico.

O plano de parto centraliza o direito à informação e à decisão na mulher, tornando-a protagonista de seu próprio parto. Assim, garante-se o respeito ao princípio bioético de autonomia e às decisões da mulher, contribuindo para seu empoderamento no processo de gerar e parir.

O uso dessa ferramenta pode garantir uma melhor qualidade da assistência para o binômio mãe e filho, contribuindo para a redução e a eliminação de atos de negligência, imperícia e imprudência, assim como pode promover a emancipação da mulher.

um plano de parto serve também para que a mulher grávida tome consciência de tudo que envolve um parto. Conhecer sobre todos os procedimentos e refletir sobre a aceitação deles ou não contribui para um melhor desfecho. Embora não seja uma lista de obrigações à equipe, ele é um documento que permite que os envolvidos no atendimento conheçam os desejos da mãe e estimula que a mulher esteja mais bem preparada para conversar com os médicos e enfermeiros sobre seus desejos, escolhas e prioridades. A gestante tem o direito de saber exatamente os benefícios e prejuízos que cada procedimento, exame ou manobra médica pode provocar a ela e/ou ao seu bebê.

Este trabalho pode ajudar a justificar o uso do plano de parto pelos profissionais da área de saúde, principalmente o enfermeiro, que poderão utilizálo como estratégia para substanciar sua prática do cuidado.

Salienta-se a importância e a necessidade de estudos e pesquisas sobre o plano de parto, pois infelizmente há escassez de publicações nacionais sobre o plano de parto. Há escassez também relacionando o tema como ferramenta utilizada durante a assistência de enfermagem, evidenciando a necessidade de pesquisas que apresentem resultados e reflexões sobre a importância da enfermagem para a elaboração do plano. Isto fortaleceria a categoria e daria maior respaldo. 
As escolhas no parto de baixo risco devem ser da mulher, e não dos profissionais, afinal, o protagonismo é dela.

\section{REFERÊNCIAS}

BRASIL. Ministério da Saúde. Secretaria de Atenção à Saúde. Área Técnica de Saúde da Criança e Aleitamento Materno. Além da Sobrevivência: Práticas integradas de atenção ao parto, benéficas para a nutrição e a saúde de mães e crianças. Brasília, 2011. BRASIL.

Ministério da Saúde. Secretaria de Atenção à Saúde. Departamento de Atenção Básica. Caderno de Atenção Básica n³2 - Atenção ao Pré-Natal de Baixo Risco. Brasília, 2012.

CORTÉS, Maria Suárez et al. Uso e Influencia dos Planos de Parto e Nascimento no Processo de Parto Humanizado. Revista Latino-americana de Enfermagem, Ribeirão Preto, v.23, n.03, p.520-526, 2015.

PORTO ALEGRE. Secretaria Municipal de Saúde de Porto Alegre. Protocolo de Assistência ao Pré-Natal de Baixo Risco. Porto Alegre, 2015.

BRASIL. Lei $\mathrm{n}^{\circ}$ 11.108, de 7 de abril de 2005. Lei do Acompanhante. Brasilia,2005.

CALIL, Maria Flor. 2016. O Plano de Parto. Disponível em: $<$ https://bebe.abril.com.br/parto-e-pos-parto/entenda-como-funciona-o-planode-parto/>.

JORDANO, Andressa. Parto humanizado: Empoderamento feminino em um grande momento da vida da mulher. Disponível em: <http://inovasocial.com.br/empoderamento/parto-humanizado-empoderamentofeminino/> .

SANTOS, Silvéria Maria. 2016. Empoderamento feminino desde a gestação até o parto. Disponível em: <https://www.unbciencia.unb.br/biologicas/58enfermagem/504-emponderamento-feminino-desde-a-gestacao-ate-o-parto>. 
NOGUEIRA et.al. Ferramentas para o empoderamento de mulheres durante a assistência de enfermagem. Rev Enferm UFSM 2017 Jan/Fev.;7(1): 144-15. HELENA, Beatriz. 2018. Plano de parto: o que é e como fazer um. Disponível em: $\quad<h t t p s: / / w w w . v i x . c o m / p t / b d m / b e b e / 8238 /$ plano-de-parto-o-que-e-e-comofazer-um >

NEVES, Raquel. 2017. Exemplo de um Plano de Parto para preparar o grande momento. Disponível em: <http://www.vidaativa.pt/a/plano-de-parto/>. 